\title{
Growth, Inequality and Politics Revisited: A Developing-Country Case
}

\author{
Arsenio M. Balisacan \\ University of the Philippines-Diliman \\ and \\ Nobuhiko Fuwa \\ International Rice Research Institute \\ and \\ Chiba University
}

\begin{abstract}
Key issues in the empirical study on growth are addressed using provincial data in the Philippines. We find a high rate of absolute convergence, a positive relationship between inequality and growth, and a positive relationship between political competitiveness and growth.
\end{abstract}

JEL classification: O4 I3 O53 P16

Key words: economic growth; convergence; inequality and growth; politics and growth; the Philippines

Corresponding author: Arsenio M. Balisacan, School of Economics, University of the Philippines, Diliman, Quezon City 1101, Philippines; Tel: (63 2) 9205466; Fax: (63 2) 9264615; E-mail: ambalisacan@ skyinet.net. 


\section{Introduction}

This paper addresses some of the key issues in the empirical study on economic growth using the provincial income growth between 1988 and 1997 in the Philippines as the unit of observation. We adopt the neoclassical growth framework by Barro and Sala-i-Martin (1995), hereafter BS, and examine the rate of absolute convergence across provincial incomes, the relationship between initial inequality in land distribution and subsequent income growth, and the effects of the degree of political competition on growth.

The use of sub-national level data has major advantages in addressing these issues over cross-country regression studies. The data comparability issue, for example, is less serious within a country than across countries. While the comparison of political characteristics across countries can be difficult due to the diversity in historical experiences, cultural norms and institutional contexts, sub-national level studies can control for such contexts and focus on specific aspects of the political system, such as the degree of competitiveness among political actors.

\section{Evidence on Provincial Convergence}

Figure 1 shows the relationship between the per capita expenditures in 1988 and the average annual growth rate of per capita expenditures between 1988 and 1997, suggesting a pattern of absolute ' $\beta$-convergence'. $\square$ We first replicated, using our Philippine data, BS's

\footnotetext{
${ }^{1}$ The focus is on per capita expenditures rather than per capita income, as is the standard in cross-country regression studies, simply because measured intra-national expenditures are invariably less variable than measured income and that accurate information is also less difficult to obtain for consumption than it is for income (Deaton 2001).
} 
analysis (chapter 11) of regional convergence in the United States, Japan and Europe by estimating:

$$
(1 / 9) \log \left(\text { PCEXP97./PCEXP88 }_{\mathrm{i}}\right)=\alpha-\left[\left(1-\mathrm{e}^{-9 \beta}\right) / \mathrm{T}\right] \log \left(\mathrm{PCEXP}_{\mathrm{i}}\right)+\mathrm{u}_{\mathrm{i}},
$$

where PCEXP88 ${ }_{\mathrm{i}}$ and PCEXP97 $\mathrm{i}$ are the per capita expenditures for province $\mathrm{i}$ in 1988 and 1997 respectively, and $u_{i}$ is the error term. We obtained an estimated rate of convergence $(\beta)$ of 0.107 .2 The standard deviation of the log of per capita expenditures across provinces also fell from 0.303 in 1988 to 0.239 in 1994 ( $\sigma$-convergence). Nor do we find an indication of 'twin-peakedness' by inspecting the kernel density of the per capita expenditures between 1988 and 1994, in contrast with Quah's (1996) observations based on cross-country data (Figure 2).

Compared to BS's $\beta$ coefficients for currently developed countries, which are clustered around $2 \%$, the comparable estimate from the Philippines is strikingly high. With a $\beta$ of $2 \%$, the number of years required to halve the gap between the initial and the steady-state incomes is 35 years; with a $\beta$ value of $10.7 \%$, the half-life is only 6 years. Our finding, however, has little to say about international income convergence; in fact, the high speed of convergence could imply that the observed income levels could (already) be close to the steady-state level, and that provincial incomes within the Philippines may well be converging toward a low-level steady-state by international standards. Interpreting our results in reference

\footnotetext{
${ }^{2}$ The potential bias due to the possible correlation between the initial income and the unobserved provincial-specific effects here is likely to be less serious than in cross-country estimates, since the main sources of such heterogeneity (technologies, tastes, etc.) tend to be similar within a country. Furthremore, Casseli et al. (1996) show such bias to be unambiguously downward; thus, our main qualitative finding of a high convergence rate would not be affeted (but rather enhanced).
} 
to neoclassical growth theories, the high rate of convergence is consistent with open economy versions of growth models, and with 'non-augmented' production function models with relatively low capital shares (e.g., BS, Caselli et al. 1996).

\section{Determinants of Provincial Income Growth}

We continue to follow the neoclassical framework to explain the differential rates of income growth across provinces by estimating the following equation:

$$
\mathrm{GRPCEXP}_{\mathrm{i}}=a+b \log \left(\mathrm{PCEXP}_{\mathrm{i}}\right)+\Sigma \mathrm{G}_{\mathrm{k}} \mathrm{X}_{\mathrm{ik}}+\mathrm{u}_{\mathrm{i}}
$$

where GRPCEXP is the annual average growth rate of per capita expenditures between 1988 and $1997, \mathrm{X}_{\mathrm{k}}$ is a set of additional explanatory variables and $\mathrm{u}_{\mathrm{i}}$ is the error term. We initially included the following variables as the potential explanatory variables ${ }^{3}$.

(1) Initial economic conditions: mortality rate per 1000 of children aged 0-5; simple adult literacy rate; proportion of irrigated farm area to total farm area; Gini ratio of farm distribution.

(2) Initial political characteristic: political 'dynasty' (proportion of key provincial officials-governors, vice governors, and district-level representatives to the House of Representatives_-related to each other by blood or affinity, as a proxy for political competitiveness).

\footnotetext{
${ }^{3}$ Cross-section growth regressions are potentially subject to endogeneity bias (e. g., Caselli et al. 1996). We would expect, however, that land distribution and 'political dynasty' are reasonably stable over time and thus likely to be relatively less 'endogenous.' We discuss below the potential endogeneity of land reform.
} 
(3) Time-Varying Policy variables (difference between 1988 and 1997) 9 agricultural terms of trade (the ratio of implicit price deflator for agriculture to implicit price deflator for non-agriculture); electricity access (the proportion of households with electricity); road density; Comprehensive Agrarian Reform Program(CARP) implementation (the proportion of cumulative CARP accomplishments—i.e., cumulative area acquired and distributed to tenants and landless workers - to 1990 potential land reform area).

Estimation results are shown in Table 1. In the specification reported in column (2), all the insignificant variables are dropped. Among the initial conditions, the human capital stock, as measured by child mortality rate, has significant effects in raising the steady-state income level. Furthermore, we find significantly positive effects of the inequality in land distribution; on average, a one standard deviation increase in the Gini coefficient is associated with a 0.7 percentage point increase in growth rates. with Forbes's (2000), the latter focuses on the relationship between initial income inequality and growth and our findings on the positive effects of the initial land inequality is difficult to interpret (e.g., Deininger and Squire 1998).

One possibility is that there emerged productivity differentials between small and large farms in the 1990s. While the lack of economies of scale in developing agriculture, including that of the Philippines, is well documented (e.g., Hayami et al. 1990), Hayami and Kikuchi (1999) recently reported significantly higher rice yields among large farms than among small farms in a Laguna village as of 1995-due to the introduction by large farmers

\footnotetext{
4 Agricultural terms of trade and CARP are defined at the 'regional' level, a higher-level aggregation of provinces, due to lack of data.

${ }^{5}$ We also experimented with alternative measures of land distribution but found qualitatively similar results.
} 
of pump irrigation in response to the deterioration of the national irrigation system-even though they had not found scale-based productivity differentials during the 1970s and the 1980s. They contend, however, that, if rental markets for pumps develop - as was the case with tractors introduced earlier — such productivity differentials would (again) disappear. We should perhaps be cautious in drawing a definitive policy conclusion at this point regarding the trade-off between growth and equity.

The 'dynasty' variable has significantly negative effects on growth. We confirm the common argument in the literature on the Philippine politics that the lack of competitive political system has been a main reason for the sub-optimal policy choices and thus for the poor economic performances compared to its Asian neighbors (e. g., Hutchcroft 1998).

The only significant policy variable is the CARP implementation; a one standard deviation increase in the land reform accomplishment is associated with a 0.7 percentage point increase in growth rates. While this finding appears to contradict the positive relationship between land inequality and growth, land reform could affect growth through non-agricultural routes; land reform re-distributed income from landowners to former tenants, who subsequently invested in education and non-agricultural activities, which, in turn, emerged as the main source of the income growth in rural Philippines (e.g., Estudillo and Otsuka 1999, Hayami and Kikuchi 1999). Alternatively, CARP implementation could be endogenous, which is consistent with Otsuka's (1991) finding that land reform progressed faster in the regions with greater agricultural growth potentials. 
Acknowledgment: The work leading to this paper was funded by the World Bank. The authors would like to thank Sharon Faye Piza and Rashiel Velarde for excellent research assistance, and seminar participants at the University of the Philippines, IRRI, and FASID for helpful comments and suggestions.

\section{References}

Barro, R.J. and X. Sala-i-Martin, 1995, Economic Growth (MIT Press, Cambridge).

Caselli, F., et. al., 1996, Reopening the Convergence Debate, Journal of Economic Growth 1, 363-389.

Deaton, A., 2001, Counting the World's Poor: Problems and Possible Solutions, World Bank Research Observer, 16(2), 125-147.

Deininger, K. and L. Squire, 1998, New Ways of Looking at Old Issues: Inequality and Growth, Journal of Development Economics, 57, 259-287.

Estudillo, J.P. and K. Otsuka, 1999, Green Revolution, Human Capital, and Off-Farm Employment: Changing Sources of Income among Farm Households in Central Luzon, 1966-94, Economic Development and Cultural Change, 47(3), 497-524.

Forbes, K., 2000, A Reassessment of the Relationship between Inequality and Growth, American Economic Review, 90, 869-887.

Hayami, Y. and M. Kikuchi, 1999, A Rice Village Saga: Three Decades of Green Revolution in the Philippines (Barnes \& Noble, New York).

Hayami, Y., et. al., 1990, Toward An Alternative Land Reform Paradigm: A Philippine Perspective (Ateneo de Manila University Press, Quezon City).

Hutchcroft, P., 1998, Booty Capitalism: The Politics of Banking in the Philippines (Cornell University Press, Ithaca).

Otsuka, K., 1991, Determinants and Consequences of Land Reform Implementation in the Philippines, Journal of Development Economics 35, 339-355.

Quah, D., 1996, Twin Peaks: Growth and Convergence in Models of Distribution Dynamics, Economic Journal 106, 1045-1055. 
Table 1. Determinants of Provincial Growth: Instrumental Variable Estimation (t-ratios in parentheses)

\begin{tabular}{|l|c|c|}
\hline Independent variable & $(1)$ & $(2)$ \\
\hline Log (Per capita expenditure & $\mathbf{- 0 . 0 8 8 ( 1 0 . 2 4 )}$ & $\mathbf{- 0 . 0 8 5}(\mathbf{1 1 . 5 9})$ \\
1988) & & \\
\hline Mortality rate $^{2}$ & $\mathbf{- 0 . 0 0 1 ( 3 . 0 4 )}$ & $\mathbf{- 0 . 0 0 0 7}(\mathbf{- 4 . 3 7 )}$ \\
\hline Literacy rate $^{3}$ & $0.0001(0.16)$ & \\
\hline Dynasty $^{4}$ & $\mathbf{- 0 . 0 2 6}(\mathbf{2 . 2 4})$ & $\mathbf{- 0 . 0 2 2}(\mathbf{2 . 1 7})$ \\
\hline Irrigation area $^{5}$ & $0.002(0.14)$ & \\
\hline Land Gini $^{5}$ & $\mathbf{0 . 0 0 1 ( 3 . 0 5 )}$ & $\mathbf{0 . 0 0 1}(\mathbf{3 . 4 1})$ \\
\hline Chg. CARP $^{6}$ & $\mathbf{0 . 0 0 6}(\mathbf{2 . 1 1})$ & $\mathbf{0 . 0 0 6}(\mathbf{3 . 1 5})$ \\
\hline Chg. Electricity $^{1}$ & $-0.00003(0.13)$ & \\
\hline Chg. Ag. terms of trade $^{7}$ & $0.016(0.52)$ & \\
\hline Chg. Road density $^{8}$ & $0.018(0.64)$ & $0.833(10.59)$ \\
\hline Constant & $0.849(8.52)$ & 0.6967 \\
\hline Adj. R-squared & 0.6799 & 70 \\
\hline Sample size & 65 & \\
\hline
\end{tabular}

Data sources: ${ }^{1}$ Family Income and Expenditures Survey, National Statistics Office (NSO); ${ }^{2} 1990$ Women \& Child Health Indicators; ${ }^{3}$ Functional Literacy, Education, and Mass Media Survey, NSO; ${ }^{4}$ Commission on Elections and interviews by authors; ${ }^{5}$ Census of Agriculture, NSO; ${ }^{6}$ Department of Agrarian Reform; ${ }^{7}$ Regional Accounts of the Philippines, National Statistical Coordination Board; ${ }^{8}$ Department of Public Works and Highway. 
Figure 1. Absolute Convergence of Provincial Income Growth

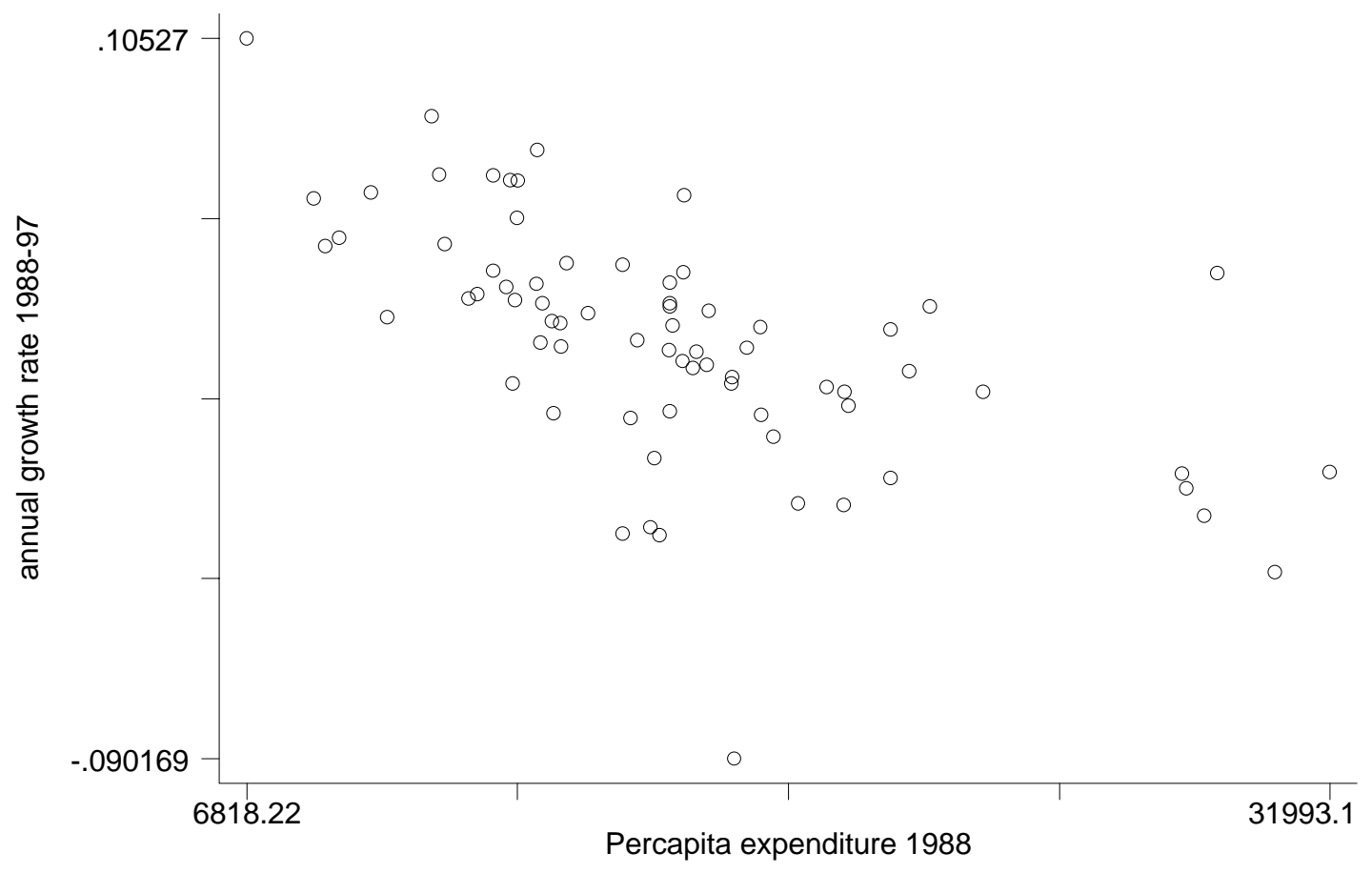


Figure 2. Kernel Density of Log of Per Capita Expenditures: 1988 vs. 1997

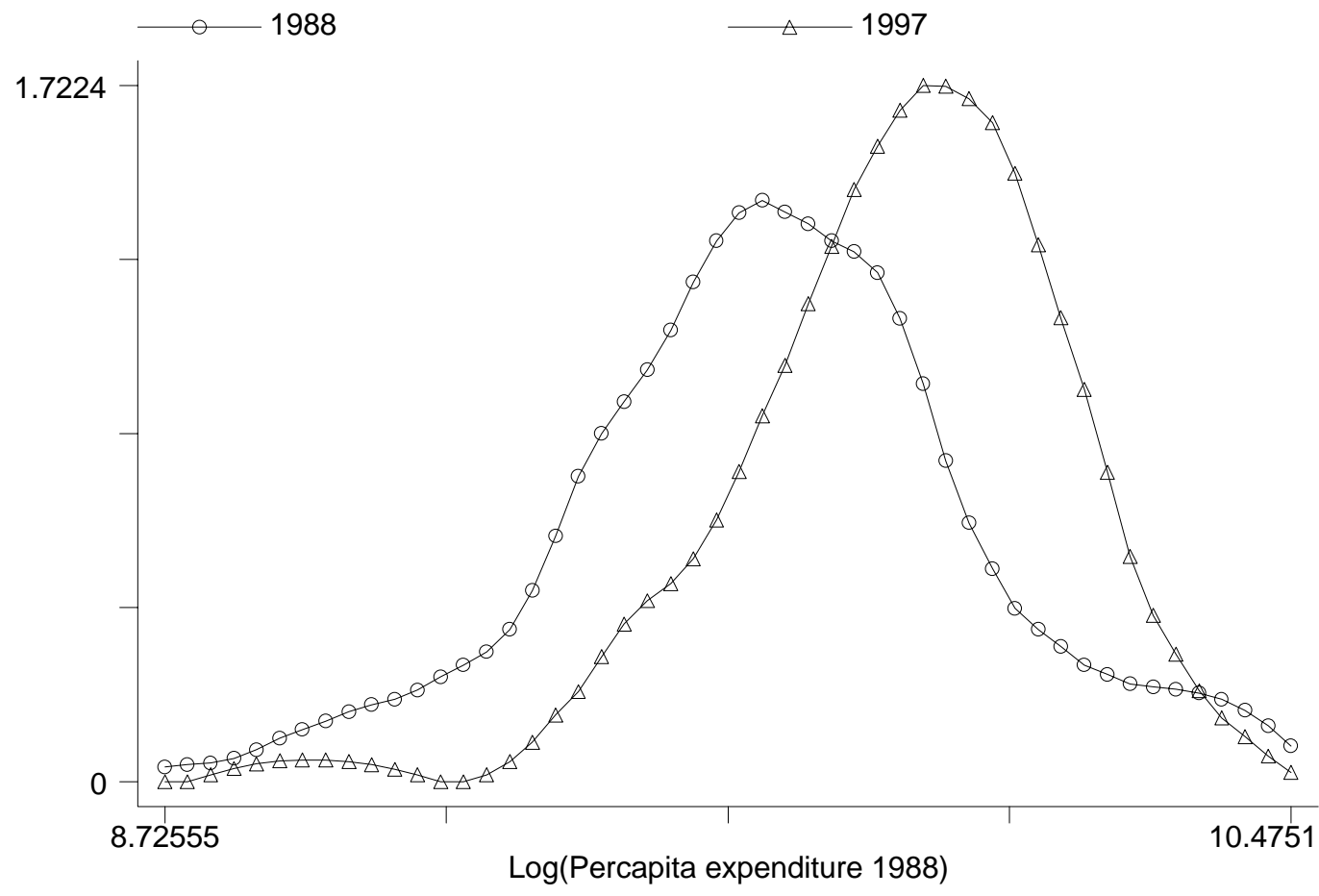

